\title{
FETAL MESENCHYMAL STEM CELL BIO MARKING FOR TRACKING CELLS
}

\author{
*A.MANGALA GOWRI ${ }^{1}$, M. RAJASUNDARI ${ }^{2}$ and G.DHINAKAR RAJ ${ }^{3}$ \\ *1- Associate Professor, 2-Senior Research fellow, 3 - Professor and Head, \\ Dept. of Animal Biotechnology, Madras Veterinary College, Chennai-7, Tamil Nadu, India.
}

\begin{abstract}
Stem cells have the ability to differentiate into different types of cells and unique property of self renewal. Thus it is suitable for replacement therapies and regenerative medical applications. Besides hematopoietic stem cells (HSCs), bone marrow (BM) possess marrow cells called as mesenchymal stem cells (MSCs) or stromal stem cells that are present in bone marrow. MSCs are multipotent precursors present in adult BM, having the ability to differentiate into osteoblasts, adipocytes, chondrocytes, tenocytes and myoblasts (Pittenger et al.,1999; Bianco et al., 2001). Although MSCs represent a very small fraction of the total population of nucleated cells in the marrow $(0.01 \%-0.001 \%$, Pittenger et al., 1999) they can be easily separated from the HSCs by their adherence to plastics and glasses (Colter et al., 2000). Green fluorescent protein has been used widely as a marker for tracking cells in a wide variety of cell biology studies. Since MSCs are gaining importance for their potential in clinical application the present study has been done to assess the efficiency of GFP marking in ovine fetal mesenchymal stem cells and thus evolve suitable method for tracking these cells in transplantation in pharmacologic applications.
\end{abstract}

Key Words: Bone Marrow,Mesenchymal Stem Cells, Green fluorescent protein, biomarking

\section{INTRODUCTION}

Stem cells derived from bone marrow is a promising source for regenerative medicine and cell based therapies. But the identity of the cells transplanted and their contribution in tissue repair remains challenging due to deficient cell tracking methods. GFP is a protein absorbs blue light and emits green fluorescence without exogenous substrates or cofactors and provides a convenient and efficient way to identify labeled cells. Transfection is the method of choice to insert plasmid DNAs, RNAs, siRNAs, and miRNAs into the eukaryotic cells. Transfected cells can express the foreign molecules transiently or permanently. But permanent expression is desired. A variety of methods are used for transferring GFP plasmid, such as microinjection, electroporation, calcium phosphate, DEAE-Dextran, liposome and retro viral mediated transfer (Rane et al., 1998;Carlesso et al., 1999; Perkins et al.,2000; Zhong et al., 2004). The present study has been done with oligofectamine transfection reagent. This method is found to be less toxic to the cells, stable expression of GFP in vitro was possible for more than three weeks and in three continuous passages.

\section{MATERIALS AND METHODS}

Bone tissue obtained from slaughter house fetuses were processed immediately after slaughter to obtain marrow cells. These cells were purified by gradient centrifugation with Ficoll paque (Sigma). The cells were plated at a density of $1 \times 10^{6}$ cells in plastic $25 \mathrm{~cm}^{2}$ culture flasks (Nunc) in MSC growth medium (MSCGM).The culture medium was changed periodically to remove the unattached cells over a period of 24 to $48 \mathrm{hrs}$ to arrive at pure adherent cell population. The cells were routinely cultured in complete medium consists of RPMI 1640 containing 10\% fetal calf serum (Gibco), 2 Mmol/ L-glutamine, 100 $\mathrm{U} / \mathrm{ml}$ of penicillin $\mathrm{G}$ sodium and $100 \mathrm{ug} / \mathrm{ml}$ of streptomycin sulfate in a humidified atmosphere of $5 \% \mathrm{CO}_{2}$ at $37^{\circ} \mathrm{C}$. The confluent adherent population was selected for CD34- cells by magnetic activated cell separation (Millitenyi Biotech). The purified population was cultured and the adherent spindle cells were used for transfection.

Bacterial strain Escherichia coli DH5a were used to propagate and prepare recombinant plasmid GFP. The recombinant plasmid was extracted by high pure plasmid extraction kit (Biosource). GFP expressing cell establishment was done by transfection of MSCs by GFP. Third passage cells derived from bone marrow showing mesenchymal stem cellular characteristics were transfected with the pEGFP-C1vector (Clontech) using the transfecting reagent Oligofectamine (Invitrogen). 24 hrs prior to transfection $1 \times 10^{6}$ cells were cultured in serum free RPMI 1640 medium without antibiotics in 6 well plates. For transfection following dilutions were made: one $\mu \mathrm{l}$ of $20 \mathrm{mM}$ stock of oligonucleotide in $16 \mu 1$ of medium and $0.6 \mu \mathrm{l}$ of oligofectamine in medium to make a final volume of $3 \mu \mathrm{l}$. After gentle mixing incubated for 10 minutes at room 
temperature and added to the cells and incubated at $37{ }^{\circ} \mathrm{C}$ for $4 \mathrm{hrs}$. After $4 \mathrm{hrs}$ medium was supplemented with $3 \mathrm{x}$ concentration of serum without removing the transfection mixture.

\section{RESULTS}

Mesenchymal stem cells were typically identified as plastic adherent, spindle shaped cells that grow in monolayer showing varying cellular morphology. The cells showed slender elongated morphology and a cuboidal shape with cytoplasmic projections (Fig). The initial pure population ( 24 to $72 \mathrm{hrs)} \mathrm{showed} \mathrm{glistening} \mathrm{round} \mathrm{cells} \mathrm{starts} \mathrm{adhering} \mathrm{to} \mathrm{the} \mathrm{surface} \mathrm{of}$ culture dish. These cells starts flattenening, assume fibroblastic morphology and show spindle shaped cells which attained confluency in around 21 days. Cells were passaged in the split ratio of 1:3 and the third passage cells were used for transfection.

The concentration of plasmid used was $90.3 \mu \mathrm{g} \pm 0.03 / \mathrm{ml}$ on various trails and was checked on $1 \%$ agarose gel. MSCs were grown in $25 \mathrm{~cm}^{2}$ culture flask in a density of $1 \times 10^{6}$ cells in $5 \mathrm{ml}$ medium and transfection of MSCs with GFP was conducted using Oligofectamine transfecting reagent (Invitrogen). Transfection was performed as per the instructions of the manufacturer. Expression of green fluorescent protein was observed at various intervals from 24 to $96 \mathrm{hrs}$ (Fig). The cells were replaced with medium containing antibiotics for two weeks and this protocol resulted in stable expression of GFP in mesenchymal stem cells.

\section{DISCUSSION:}

Friedenstein et al., (1979) were the first to isolate MSCs using their ability to adhere to plastics culture surface and this property has been a common characteristics to isolate potential MSC population (Taylor and Smith, 2007). The present study showed cell morphological characteristic that correlates well with the reports of Friedenstein et al., (1976) and these cells were positive for mesenchymal stem cell specific cell surface markers such as CD 44, CD 54 and intracellular expression of collagen type I.

Stem cells application in clinical therapy can be ascertained by the tracking of these cells after transplantation in vivo. pEGFP-C1 encodes a red shifted variant of wild type GFP which has been optimized for brighter fluorescence and higher expression in mammalian cells (excitation maximum $=488 \mathrm{~nm}$, emission maximum $=507 \mathrm{~nm}$ ). Marking these cells with GFP vectors track the transfected cells and used as a potential marker in analyzing the various biological activities of transplanted cells. There are a variety of methods available to mark the cells used in cell therapy but only few methods show stable expression of cells. Meier and collegues (2001) showed that effectene transfection method has got low toxicity in neuronal cells. Also it has been established that this method could be done in complete medium. Tomiyama et al., (2007) applied this strategy to study the BM cells in adipose tissue in rat. The removal of transfecting reagent from the cells around $8 \mathrm{hrs}$ after transfection and addition of fresh medium could result in more efficient transfection. The removal of transfection reagent could prevent apoptotic changes and presence of dead cells. More than one dose of plasmids twice (during 24 hrs and at 48 hrs) enhanced the efficiency of transfection ( $\mathrm{p}<0.05, \mathrm{p}<0.05$ ). The fluorescence was stably present during of $24,48,72$ and $96 \mathrm{hrs}$ after transfection in culture. Hence these procedures can be an easily applicable method for tracking the MSCs transferred to tissues and living system and fulfills the contemporary need.

\section{REFERENCES}

6. P Bianco, M Riminucci, S Gronthos and PG Robey, Bonemarrow stromal stem cells: Nature, Biology and potential applications. Stem cells. 19, 2001, 80-92.

7. N Carlesso, JC Aster, J Sklar and DT Scadden. Notch 1- induced delay of human hematopoietic progenitor cell differentiation is associated with altered cell cycle kinetics. Blood, 93, 1998, 38-48.

8. DC Colter, R Class, CM DiGirolamo and DJ Prockop. Rapid expansion of recycling stem cells in cultures of plastic adherent cells from human bone marrow. Proc Natl Acad Sci USA 97, 2000 , 3213-8.

9. AJ Friedenstein, UF Gorskaja, MN Kulagina. Fibroblast precursors in normal and irradiated mouse hematopoietic organs. Exp Hematol 4, 2000, 267-74.

10. J Meier, C Vannier, A Serge, A Triller, D Choquet. Fast and reversible trapping of surface glycine receptors by gephyrin. Nat Neurosci, 4, 2001, 253-60.

11. CL Perkins, G Fang,CN Kim and KN Bhalla. The role of Apaf-1, Caspase-9 and bid proteins in etoposide- or paclitaxel- induced mitochondrial events during apoptosis. Cancer Res, 60, 2000, 1645-53

12. MF Pittenger, AM Mackey, SC Beck, RK Jaiswal,R Douglas, JD Mosca, MA Moorman, DW Simonetti, S Craig and DR Marshak. Multilineage potential of adult human mesenchymal stem cells. Science 284,1999.143-7.

13. MJ Rane , JM Arthur, ER Prossnitz and KR Mcleish. Activation of mitogen activated protein kinases by formyl peptide receptors is regulated by the cytoplasmic tail. J Biol chem. 273, 2004, 20916-23. 
14. S E Taylor, RKW Smith and PD Clegg. Mesenchymal stem cell therapy in equine musculoskeletal disease. Scientific fact or clinical fiction? Equine Veterinary Journal: 39, 2007, 172-80,

15. K Tomiyama, N Murase, DB Stolz, H Toyokawa, DR O' Donnell, DM Smith, JR Dudas,JP Rubin and KG Marra. Characterization of transplanted green fluorescent protein + bonemarrow cells into adipose tissue. Stem cells, 26, 2008, 330-8.

16. $\mathrm{X}$ Zhong and AR Safa, RNA helicase A in the MEF1 transcription factor complex up-regulates the MDR 1 gene in multidrug-resistant cancer cells. J Biol chem., 279, 2004,17134-41.

\section{ACKNOWLEDGEMENT}

The present findings are part of the research in the DBT, GOI funded project 'Mesenchymal stem cell therapy for induced skin and burn wounds in mice'. The authors place their sincere acknowledgement to the Department of Biotechnology, Government of India (DBT, GOI) New Delhi for funding to carry out the present research and TANUVAS for the facilities provided for the study.

Fig 1 Microphotograph showing mesenchymal stem cells
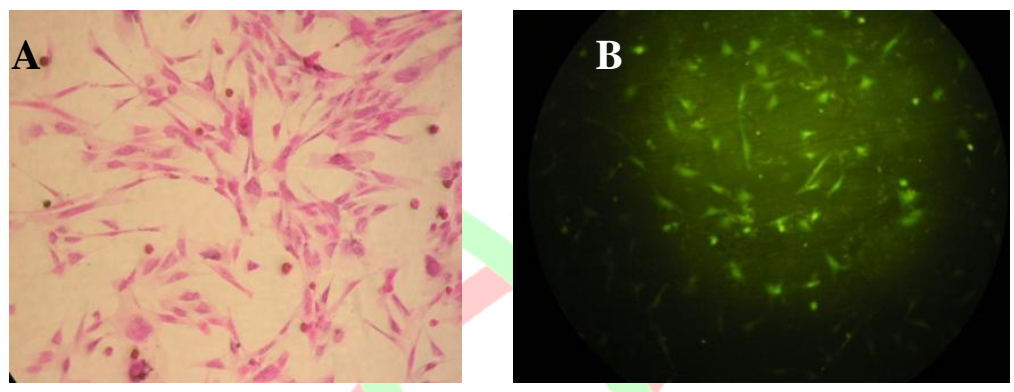

Fig A- Micrograph of mesenchymal stem cells showing spindle morphology(H\&E stained $200 \mathrm{x})$.

Fig B - Fluorescent micrograph of mesenchymal stem cells transfected with GFP at 48 hrs (100x). 